Wilfrid Laurier University

Scholars Commons @ Laurier

Partnerships for Children and Families Project

Reports and Papers

$6-2002$

\title{
Learning From Difference: Comparing Child Welfare Systems
}

\author{
Rachael Hetherington \\ Wilfrid Laurier University
}

Follow this and additional works at: https://scholars.wlu.ca/pcfp

Part of the Family, Life Course, and Society Commons, and the Social Work Commons

\section{Recommended Citation}

Hetherington, R. (June 2002). Learning from difference: Comparing child welfare systems. Keynote Address at the Positive Systems of Child Welfare Conference, Waterloo, ON.

This Positive Systems of Child and Family Welfare International Conference (2002) is brought to you for free and open access by the Reports and Papers at Scholars Commons @ Laurier. It has been accepted for inclusion in Partnerships for Children and Families Project by an authorized administrator of Scholars Commons @ Laurier. For more information, please contact scholarscommons@wlu.ca. 


\section{Partnerships for \\ Children and Families \\ Project}

Learning from Difference: Comparing Child Welfare Systems

R. Hetherington

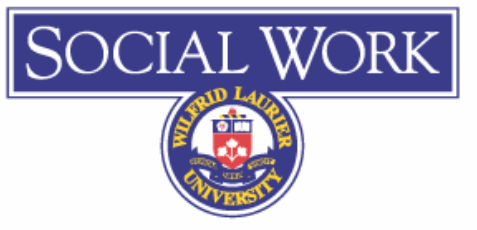

June 2002 


\title{
Learning From Difference: Comparing Child Welfare Systems
}

\author{
Rachael Hetherington
}

\begin{abstract}
Child welfare and child protection are integral aspects of the welfare regimes of all post-industrial societies. However, although the needs of children and the dangers of child abuse are so widely acknowledged, the ways in which these needs and risks are met varies considerably, even between countries with similar structures. By studying the ways in which other countries deal with similar problems, we can learn about new ways of responding and may find ideas that we can adapt for use in our own context. But we can do much more than this. By looking at differences, and using the power of making comparisons, we can begin to understand more about our own system and why it has developed as it has. We can begin to identify the 'taken-for-granted'. This may lead us to question some of the assumptions on which our system rests and to become more aware of the aspects of our system that we value most highly. As we become more aware of the reasons why our system has developed as it has, positive changes may become more attainable.
\end{abstract}




\title{
Learning From Difference: Comparing Child Welfare Systems
}

\author{
Rachael Hetherington
}

\section{Introduction}

Learning from difference is a complex process. This paper describes that process and considers the problems and benefits of working with inter-country comparisons. The author's interest in this stemmed from the work of the Centre for Comparative Social Work Studies (CCSWS), Brunel University ${ }^{1}$. Initial attempts to describe another child protection system led us, through the exploration of difference and similarity, to a new understanding of our own child welfare system, and to a consideration of the role of the wider culture of society in determining these systems. Social workers and social work academics are familiar with working across the boundaries that define the disciplines of psychology, sociology and social policy. Working with cross-country comparisons adds a whole range of linguistic, social and historical considerations to the relevant disciplines. What we found might be obvious to experts in those fields, but what we have found is fresh for us, and it has provided us with a new slant on old problems.

This paper falls into two parts. The first part describes the process of making comparisons. After a brief account of the context of comparative studies relating to child welfare, the methodology of the research projects on which this paper is based is described. The process of learning from difference is analysed and three stages of the process are outlined. The second part of the paper uses comparative studies to analyse the factors that determine the functioning of child welfare systems, and raises questions about the relationship between child welfare systems and the wider socioeconomic systems within which they function. The implications for creating change in child welfare systems are discussed. 
For simplicity, the systems we studied will be referred to as child welfare systems throughout, on the grounds that both child protection and family welfare are always an aspect of child welfare. Where the term 'child protection' is used, this is done with the narrow meaning of services or systems that focus on child rescue. References throughout this paper are to England rather than the United Kingdom because the child welfare systems of England, Scotland and Northern Ireland are not the same. Wales shares the same system as England, but our research was conducted in England, and can only be taken as relating to England.

\section{The context in comparative studies}

Comparative research as a means of studying social welfare systems is well established and there is a considerable body of work comparing the welfare benefits and health service systems of European countries ${ }^{2}$. However, using comparison to study social welfare structures has many problems, because of the difficulty of establishing what is truly the same or different. Jones singled out social work as a particularly intractable area of study calling it, 'a messy area for research' (Jones 1985, p. 172). In the field of child welfare, there are some single country studies, where there is no comparative element either in the authorship or the editing (for example, Hellinckx, Colton \& Williams (1997). These studies provide useful source material from which comparisons can be developed. There are a few studies that are overtly comparative such as Miller \& Warman (1996), Gilbert (1997) and Pringle (1998). However, although there has been a considerable increase, particularly in the European context, of descriptions of other systems, there is still a shortage of information which is directly based on practice and which also takes account of the structural context in which the work takes place ${ }^{3}$. 
Two comparative studies are described here in more detail, as there will be later reference to them. In 1990, Esping-Andersen published a seminal study of welfare regimes, in which he suggested a categorisation according to the underlying socio-economic philosophy of the state. Welfare regimes were typified as socialdemocratic, conservative or liberal. The Scandinavian countries were grouped as social-democratic, the continental European countries as conservative, and the English speaking countries as liberal. Subsequent studies of welfare regimes have challenged or modified some of his conclusions, but the main outline remains intact.

In the social work field, Gilbert (1997) brought together studies of child abuse reporting systems in nine countries. Comparing them, he differentiated between those that had a 'family service' orientation and those that had a 'child protection' orientation. The countries with a family service orientation did more preventive work, and offered more family support more readily, and at an earlier stage. The countries with a child protection orientation delayed intervention and were less optimistic about the effectiveness of intervention. Their response to situations was more legalistic. The three English speaking countries in his sample, North America, Canada and England, had a child protection orientation. The other countries, Sweden, Denmark, Finland, Belgium, Germany and the Netherlands, all had a family service orientation. Gilbert also describes a further divide within the family service group between the Nordic countries, which had laws requiring the reporting of child abuse and the other European countries in his sample which did not. Gilbert's work suggests that there is a major divide between the countries that focus on child protection and those which work preventively to support the family. 


\section{The cross-country projects of the CCSWS}

The starting point for the comparative studies of the CCSWS was a wish to find out how other countries in Europe responded to the problems of child abuse. In the late 1980s, following a series of child death inquiries, there was a great deal of dissatisfaction with the English system. A new act (The Children Act 1989) was being debated and preparations were being made for its implementation. There may have been some optimism about a fresh beginning, but instead arguments seemed to follow a well-worn track without advancing the discussion. To find a way of opening up this debate, we turned outwards to look for other ideas. As it is well established that child abuse is a problem in all developed countries, we assumed that other European countries have systems in place for child protection. We wanted to learn more about other approaches because we hoped to learn about new ways of responding to common problems. We wanted to know about the laws and the formal structures for child protection, and we wanted to understand what actually happens 'on the ground'; that is how the systems work in reality.

The fulcrum of our comparisons was the problem to which the task of social work was a response, the abusive or dysfunctional family situation that was raising the issue of possible intervention. The focus of comparison was to determine "what happens for this family'. As soon as there is any official intervention with a family, the system used affects the development of the case so powerfully that comparison becomes very difficult. To overcome this concern we invented an initial hypothetical

case situation, that a potential child protection problem. The same case vignette could be presented in each country, providing a basis for comparison of the actions that would, or would not, be taken and the expectations, structures, laws and resources that might be involved in the process. 


\section{The methodology of the research}

There were three sets of studies using slightly different methodologies. They all shared certain features. All focused on the practical functioning of child welfare systems. People closely involved with the operation of the system, social workers, other professionals, and parents became the sources of information. All introduced, or attempted to introduce, an element of reflective comment from the participants.

The main studies used a case vignette to elicit information about the functioning of a child welfare system and to collect an expert opinion on the comparisons between that system and another. In each participating country, a group (or groups) of social workers and other relevant professionals was established. Each group heard the same story, which was developed over several stages. The group decided what would be most likely to happen to the family in their locality. This provided a picture of the system in action.

The group then heard about the discussion and decisions made by a group in another country working on the same case material. They identified similarities and differences between the way the systems worked, as well as the anxieties and preoccupations of the social workers within these systems. In making these comparisons, they reflected on their own system, as well as on the other system.

Four sets of data could be derived from this material. The first data set was a description of the functioning of the system made by experts - the people who work in it. The second data set was information about the preoccupations and concerns of the workers who operate the system, as demonstrated by the process of their discussions (this was based on a content analysis of the verbatim transcript). The third data set was the practitioners' view of the differences and similarities between the systems. The fourth data set became the reflections of the practitioners on these 
differences. This material was supported by information about the formal structures and resources of the involved countries that was provided by the researchers.

The role of the international group of researchers was to create the case vignette, to provide information about the structures of child welfare of their own country and to work jointly as an international team on the analysis of the material. The team sought to establish the aspects of child welfare systems that were common to the countries participating and those that appeared to be specific to one country or a group of countries. In addition, the researchers in each country drew their own conclusions about the particular relevance of the comparisons for their own system.

More detailed descriptions of the methodology of the two main projects that used the vignette technique can be found in Protecting Children: Messages from Europe (Hetherington, R., Cooper, A., Smith, P. \& Wilford, G., 1997) and The Welfare of Children with a Mentally Ill Parent: learning from inter-country comparisons (Hetherington, R., Baistow, K., Katz, I., Mesie J \& Trowell, J., 2002).

The examples used in this paper are mainly drawn from the studies using the vignette technique. Other examples are taken from a project where social workers in France and England were paired and followed each others' work over a 10 month period. During this period, they visited each other five times. After each visit, they discussed what they had learned about the other system with a member of the research team. The research data derived from the transcriptions of these discussions and from the discussions at a final meeting of all the participants and researchers at the end of the project. Details about this project are given in Positive Child Protection: a view from abroad (Cooper, A., Hetherington, R., Baistow, K., Pitts, J. \& Spriggs, A., 1995). 
This paper also draws on comparative biographical work undertaken with parents who had been involved with their child welfare system. The researchers interviewed parents who gave an unstructured account of their experience of the system. The researchers analysed these transcripts and attempted to compare in meaningful ways the experiences of parents in one country with experiences in another country, given the substantial service and socio-economic contextual differences among settings. This gave a view of the possible alternative experiences of parents involved with the systems of the countries concerned. It was only possible in a few instances to have a further interview with the parent to ask for their reflections on the suggested alternatives. The biographical material that was provided by the initial interviews provided a rich source of data, and gave a further dimension to the picture of the differences between the systems, confirming the findings of the previous projects undertaken with social workers. The work with parents is discussed in Baistow, K. \& Hetherington, R., 1999, Baistow, K. \& Wilford, G., 2000 and Hetherington, R. and Piquardt, R., 2001.

\section{The value of using comparisons}

The aim of using comparison and learning from difference is to identify possible improvements in child welfare systems. When we undertook our studies of child protection systems in six European countries, we were amazed to discover that aspects of the English system that we had assumed to be necessary and normal might not exist at all in other countries. Other countries had no child protection register, no formal child protection conference and did not involve the police in child protection investigations. We found countries that had different grounds from ours for court action as well as countries where a court hearing would happen within a fortnight of referral and last for forty minutes. We found countries where decisions about 
compulsory placement in care were undertaken by a single judge, and others where elected local government members would share this decision making. We found countries where 'child protection' was understood to include the full range of protective measures including, for example, the employment rights of children and the prevention of exploitation rather than exclusively the protection from abuse within the family. There was no way of proving that one way of doing things was more successful than another. The information on outcomes was not available, moreover there was no way of arriving at a shared definition of success. Nevertheless, our ideas, and the ideas of the participating social workers, about what was possible and what was necessary, underwent a radical change. This gave us new perspectives on the problems that we saw in the English system.

\section{The process of learning from difference}

Three elements are involved in the process of learning from difference. They are description, comparison and reflection. Comparison knowledge about two things that which is familiar or known and, the 'other', which is not familiar. These two things may have some attributes that are alike and some that are not alike.

Comparisons, therefore, have to start with learning about and describing an 'other'. But all descriptions of an 'other' are based on knowledge of something that is 'like' the object you are describing. In the middle ages, people who had travelled to Africa or India tried to describe elephants when they got home. The pictures they drew from memory frequently showed the elephant with hind legs like a horse or a cow, that bend backwards at the 'knee'. Their attempt to describe the elephant was taken over by their assumptions about how a four-legged animal would look. In order to give an accurate description of something new, it is necessary to notice difference 
from something known. Trying to give a truthful and accurate description of the 'other' is a fundamental part of making comparisons. It is not easy or straightforward.

Comparing goes hand in hand with describing, but there is an inherent paradox. I have to describe the 'other' before I can know whether there are enough similarities and differences to provide a starting point for making comparisons. I cannot give an accurate description of the 'other' until I have identified the aspects of the 'other' that are the same as, or different from, my own. The resolution to this paradox lies in accepting that the process is circular not linear. You make a comparison and say 'this is like, that is not'. You attempt a description on this basis, and you realise that you have not understood something. You look again at the things that are 'like', and discover that some of them are not alike after all (and vice versa). Reflection follows from comparison, and leads to an increase in understanding, and to a more detailed and complex description. Thus, the description takes a step forward. However the process has to start with a first attempt at a straight description of the 'other' system.

\section{Describing}

For the purpose of describing a child welfare system, the factors that influence its functioning can be categorised under the three headings: structures, professional ideology, and culture. Describing a child welfare system may start with an account of the formal structures, but it must also describe how the system works on a day-to-day basis. This will be the result of a complex interaction of various structures, including the important element of resources. The professional ideology of the workers, the theories, concepts and values of the professionals who operate the system, influence how the structures are employed. The expectations, values and social philosophies of the surrounding community form the culture within which the system works. The 
families, their friends and neighbours, the professionals and the policy makers share this culture. This culture occurs simultaneously at local, regional, and national levels.

Structures, professional ideology, and culture are interconnected. Any aspect of functioning may have its origins in all three. Generally, there are multiple reasons why a system functions as it does. For example, resources can be seen as part of the structure of a system, but the extent and targeting of resources, although forming part of the structure, may express the philosophy of the culture and the value that it attaches to different processes. Resources will also be, to a greater or lesser extent, responsive to the professional ideologies of the people who are deploying them.

\section{$\underline{\text { Structures }}$}

Structures are the mechanisms through which the child welfare services are delivered. They include the way in which government is organised locally and centrally, the place of non-governmental organisations, and how central and local government relate to health and social welfare structures, and to resources. The law relating to child welfare and family support is clearly important, but other areas of the law, for example, the laws concerning confidentiality, are relevant. The structure and process of the courts also plays a part. Information is also needed about the structures and resources of other welfare and health services as well as the specific child welfare resources available locally and nationally.

Therefore, many structures play a part in the working of a child welfare system. Studying the child welfare system of another country requires extensive background knowledge. In one's own country, most of this knowledge is taken for granted, and not regarded as integral to understanding the child welfare system, but in practice it forms a part of what determines the social workers' response to a situation. Child welfare and the welfare of the family are indivisible, and families at some stage 
include adults, children, infants, women, men, the employed and the unemployed, the well and the ill. Most aspects of civil society affect families. Families are potentially involved with the full range of services such as health, welfare, the courts and legal services, income support, housing, employment, education and leisure. The organisation and the resourcing of each of these services is important. There is a wide range of relevant legislation in addition to the laws directly relating to child protection. Child welfare can be seen as a meeting point for many aspects of the organisation of the state. The structures of child welfare systems demonstrate how the state chooses to organise the interconnections between its different parts and the balance among different priorities.

\section{Professional ideology}

Structures are not the only factors that have a profound effect on the way that services function. The professional ideology of social work, the information on which the social workers base their decisions, and the theories that guide the selection and interpretation of this information, are important. Structures (organisational structures, resources and the law) provided the framework within which decisions are made and set boundaries for the range of choices available, but final choices often are made on the basis of social work theory and knowledge.

Information about the professional ideology of the social workers (and other) professionals can be gained from a study of professional training courses and from the discussions of social workers about a particular case situation. Within the groups of social workers participating in our research, the language in which discussions took place, the assumptions made about relationships, or cause and effect, demonstrated the underlying theories and conceptualisations that informed decision making. Our research suggests that there is a great deal of shared ground among social workers in 
different European countries, and the functioning of the system is influenced by the social workers' acquaintance with, and use of, theories of human growth and development (e.g., psycho-dynamic, behavioural, systemic). The social workers' use of theories of social work intervention (e.g. ecological, systemic, psychosocial, crisis intervention, task-centred), and conceptualisations of the social work task and the role of specialisation also play a part in the decision making process and the intervention options considered. However, the amount of discretionary space that a system allocates to professional judgement varies considerably from one country to another. Heavily proceduralised systems are likely to allow less space for the use of professional knowledge.

\section{$\underline{\text { Culture }}$}

Child welfare decisions are not only framed by systemic structures and influenced by the theories and information which guide professional judgement. They are also constrained and directed by the culture of the society in which the service systems exist.

By culture, I mean the nexus of views, understandings, habits of mind, patterns of living and use of language that are built up in a community, a nation or a state by the shared history, language and social circumstances in which people grow up and live. The culture of a society is pervasive. It is expressed in part through the structures of the society, but also through the use that society makes of those structures. Culture is very strongly influenced by history, but some aspects of a culture may persist unchanged over long periods. Moreover culture is variable within a society both between different sectors of society and different geographical areas. It was apparent from our comparative research that there were important inter-country 
differences between child welfare systems that were not explained by the structures of the system or the professional ideology of the workers.

Child welfare highlights relationships among individuals, families and the state, some of the fundamental building blocks of a culture. Problems relating to the well being of children are caught up in the complex network of interests among parents, children, the community and the state. Culture influences and expresses expectations of the various roles that should be played by the state, the family, and by the community in relation to the child. These expectations find expression in the functioning of child welfare systems. It is in this context that the social worker represents the state. The aspects of culture that are important for describing a child welfare system are about the relationship between the citizen and the state, and the reciprocal expectations of parents and the state about each other's role in assuring the welfare of children.

Social workers, at the same time as representing the state, are part of society, and share the expectations and assumptions about social behaviour of the rest of society. Like the users of their services, they think in ways integral to their culture. These expectations and assumptions affect the way that professional theory and knowledge are understood and used. At times social workers may, as a group or individually, differ from the general expectations of the culture within which they are working, but, in practice, they largely have to accept the boundaries of that culture.

\section{Comparing}

The central problem in making comparisons is the difficulty of establishing whether two things that appear the same are really the same; and whether two things that seem different are really different. There are problems of definition. Statistics may not be compiled using the same criteria. Unidentified differences in the division 
of spheres of influence between central and local government may mask the 'unlikeness' of apparently similar structures and responsibilities. There are problems related to the use of words. The same word can include or exclude a range of functions. Words may have wide ranges of shared meaning but differences in the implications and valuation that they carry. Semantic similarities can mask differences, and the obvious and apparently exact translation of a word may be quite misleading. The following examples from our research experience illustrate some of the pitfalls.

- 'Administratif' is used in France to describe the structures of that part of the child welfare system that does not directly involve the law on child protection and is run by the local authority. The word 'administrative' in England would probably refer to the paperwork, not the structure, and there is no one word with an equivalent usage ${ }^{4}$.

- In some countries, residential care for children and young people may be delivered partly through the education system or through employment training institutions for young adults. In other countries these institutions are part of completely different service structures. How will this be reflected in statistics?

- Is the care of children in small group homes called foster care or residential care? And how is it conceptualised?

- 'Voluntary organisations' (the usual English designation) may not be run by volunteers nor do they necessarily only work with users on a voluntary basis. The use of the term 'voluntary organisations' is therefore best avoided. 
- In England 'volunteer' has a generally positive connotation - to work as a volunteer is generally a 'good' thing to do. Elsewhere, the volunteer may be seen, more critically, as someone who takes employment from a paid worker.

- 'Education' in English is tied to academic learning. 'Education' in French is a much broader concept and includes what in English we might call 'socialisation' or 'upbringing'. It is interesting that English lacks a single word with which to translate the concept embodied in the French word.

- The term 'pedagogy', which is current in both French and German with a positive meaning related to helping children to learn, in English is usually pejorative, implying an over directive and pedantic approach. In many European countries, there is a social work profession of social pedagogy that does not appear to exist in the United Kingdom.

- In English, the word 'foster' (fostering, foster child parent) has a long history and a specific meaning, to care for a child from another family. In French there is no similar word. The translation of 'foster family' is 'famille d'accueil', a family which 'welcomes' the child. Does this mean that 'fostering' has a different meaning, or carries different implications in these countries? Is fostering used differently?

\section{Reflecting}

Reflective learning uses new knowledge about another system to enhance our knowledge of our own system. Such learning develops from self-questioning, and it requires the ability to be both reflective and critical. The questions have to move on from what is done and how is it done, to why is it done and why is it done that way. 
Being reflective requires self-awareness. I need to be aware of what I bring to the situation or subject. Where you stand affects your point of view. Where do I stand - as a woman or man, as a white person or a black person, as old or young? How may that affect my perceptions? It also requires an acceptance that subjectivity is inevitable. I cannot cease to be who I am.

I have to use this knowledge actively when thinking about a different system or way of working. The different system becomes a mirror in which I can glimpse new facets of the system within which I work, and of the way I work within that system. The examples given below illustrate how reflection on comparisons with another system can lead to a new perspective and make visible what has been assumed or taken for granted.

Reflection also requires us to be critical, in the original sense of the word, which is not to find fault but to question, to interrogate the material. Why does it work like that, why do you do it that way, why do we do it differently? Why does that system use the law so readily when we would rate the problems as relatively minor? Why do we put off using the law till things are really bad? Is their experience of using the law different from ours? Why is it such a different experience? Are we seeing the problems differently or are we thinking about the law differently? What would happen if we acted differently? What risks would we take, what would we fear? Pursuing these lines of thought leads to a reflection on what we take for granted and creates the opportunity to question whether we wish to continue to make the same assumptions. It is not necessarily about changing our assumptions; it is about making it possible to change them. 
The following examples from our research show reflective thinking in action and illustrate the kind of reflections that this approach generates.

- An English social worker discussed one of her cases with her French colleague, and pondered his response. The case involved a teenager, a refugee and recent immigrant, who wanted to leave her residential placement to live in a situation that the social worker thought was very risky. She described to her French colleague the steps that she might take to use the law to prevent the girl from leaving care. They both agreed on her assessment of the situation, but he was puzzled by her emphasis on the legal arrangements - in France the legal situation would not have been an issue. The English social worker reflected that her approach now seemed to her 'devious' and manipulative, whereas before she had viewed it simply as a practical solution. She began to think about the English legal system, and how it might affect practice.

- A group of English practitioners saw a video of a French group discussing the child protection case. One of them commented: 'their discussion was more philosophical than ours was. They didn't talk about evidence at all. We talked about it all the time. I wonder what that says about them. And I wonder what it says about us.' The social workers in the group began to reflect on their prioritisation of evidence, which they had previously taken for granted.

- An English social worker heard about the response of German social workers to the situation of the family with a mentally ill mother. She thought the German social workers had many more resources than the English did. Reflecting on the English responses to the same situation, she noted that a lack of resources began to affect how you thought about a case. You stopped trying to understand all the 
complexities of the situation if you couldn't do anything to follow up what you had understood, and your way of thinking about cases changed and became more limited.

- An English parent who had struggled, with the support of her Health Visitor, to get help from the social services department heard about a system where the social workers and the health visitors worked in the same team. She thought that this would have been helpful for her. She had highly valued the confidentiality of the English system, but she decided that the relative loss of confidentiality would have mattered less to her than the gain in communication.

In these examples, the participants were taking a critical view of their own system, and they were finding negatives. It also happened that participants began to value more highly, or become conscious of valuing highly, aspects of their own system that they had previously taken for granted. For example, the English valued the transparency of the English system and the efforts to make clear to families their rights and the procedures of the child protection process. They began to feel more positive about their own practice in this respect. They identified a major difference between themselves and their French colleagues in their approach to work with ethnic minority families, and decided that their own position reflected strongly held values. In thinking about other systems, we may often be most interested in the negative points because of the wish to improve our own system, but the positive values that we establish are important. The things that we value set the parameters of possible change. A change that might seem helpful, but which conflicts with deeply held values, is unlikely to be successful or effective. 
Comparison very easily leads to ranking and the building of hierarchies. We tend to think competitively, in terms of which system is 'best at' this or that function. In itself, this is essentially unproductive, although very difficult to avoid. But it can be productive to look at why we rank things and what we choose to rank. For example, at one international seminar, the participants from continental Europe noted that the English were interested in ranking countries according to how successful they were at preventing child deaths. This led to an exploration of the reasons why child deaths might be a greater pre-occupation for workers in some countries than others. The ranking was not useful (or realistic - the statistical information base was not there), but it was informative to question why there was felt to be a need to make such a ranking.

The description of another system is likely to introduce us to some things that are new to us, and thus to a search for things that we can copy or borrow. We hope to be able to learn from the experience of others, and we may learn about useful structures or new ways of doing things. We may get ideas about new services that we could copy or adapt. However, there are problems about transplanting ideas or structures from one country to another. The soil or the climate may not be congenial. If these problems are recognised, it may be possible to overcome them, and to compensate for differences in the context, but this depends on becoming aware of and acknowledging the assumptions that are implicit in both systems. For example, a group of Belgian social workers, from the Flemish community, attended a seminar introducing the new guidelines published by the United Kingdom Department of Health (2000), the Framework for the Assessment of Children in Need and their Families. This publication describes an assessment model to be used by social workers. It includes a theoretical exposition of the model and detailed guidelines for its implementation 
including a time scale for undertaking the work and a lengthy form to be filled in which covers all the elements of the assessment. The Belgian workers were interested in the theoretical approach, which was congenial to them, and they found the formulation of the guidelines useful. However, they did not feel that the procedures, the time scales for undertaking the work, and the forms to be filled in, would be appropriate or relevant for them. The Belgian group identified a similarity in the use of theory and a difference in the attitude to management and professionalism. This led to reflections on the nature of the difference between the Belgian and the English systems. Their own very 'flat' management style, which they had previously taken for granted, became more visible to them. The difference in their management style indicated that they would need to be selective in their borrowing, making use of the theory but not the method of operation.

\section{The interaction of culture, structure and professional ideology}

The structure, the professional ideology of social work, and the culture of the setting influence child welfare systems and are subject to change. Structures are constantly evolving. Social work has its fashions in theories and its knowledge base steadily develops. Culture is both massively resistant to change and continually shifting. These three factors may interact in a variety of ways. Any one of the three elements, structure, professional ideology, and culture, may overcome the impact of the others. The following example demonstrates how culture can affect the interpretation of theory, and therefore the action taken.

A group of German social workers and a similar English group both considered the same case, and debated whether, at one point, a child should come into care. Both groups based their response on family systems theory, and used the same framework of argument. However, they came to different conclusions because they 
had different expectations of the family, not of that particular family, but of 'the family' as a social entity. The German group thought of 'the family' as cohesive. They thought that to take the child out of her family for a while would be helpful. It would disrupt the system and make it more open to change. The English group had a less robust view of 'the family'. They thought that if the child were taken out of her family, the system would close up. The child would be excluded, and it would be difficult to get her back into her family. It appeared that cultural expectations about the family determined how theory was interpreted and used.

Another example demonstrates the impact of structure on professional ideology. Some English social workers showed a high level of anxiety when they discussed a case situation in which they wanted to take a child into care, but child protection law and procedures would not support this intervention. French social workers discussing the same case who wanted to take the child into care had no problems because their legal framework did support their professional view of the best intervention. Here differences in structures were leading to different outcomes, even though the choice suggested by social work knowledge suggested the same response. The differences in structures (the law) may also be considered to have derived from (and reflect) differences in cultures, in the expectations about the relationship between the child, the family and the state.

The above examples also illustrate the potential for conflict between the three elements of structure, professional ideology and culture. The dilemmas that may arise from collisions between culture, professional knowledge and the structures within which social workers operate are reflected in the anxieties of social workers. The greatest area of similarity between the systems studied lay in the professional ideology of the workers. There were some differences in theoretical approach 
(broadly between the English speaking countries, which were more likely to use approaches derived from learning theory than the others), but many more similarities. However, in some of the systems, the international theoretical basis of social work (and other health and welfare professions) was exposed to contrary pressures from the national or local culture within which it operated. Where there was a conflict between professional values and the culture of their society, the participating social workers were anxious and felt impotent. The position of social workers in countries that Esping-Andersen (1990) defined as liberal seemed to be particularly conflicted (Hetherington, Baistow, Katz, Mesie and Trowell 2002).

There are inter-actions among local and national cultures, structures and professional knowledge and ideologies. This interaction determines the functioning of child welfare systems, and ensures that no two systems are ever going to be identical. As the following diagram illustrates, not only do these three elements, structures, culture and professional ideology collectively determine functioning, each of them is also affected by and may be modified by the way the system functions.

Diagram 1: The interplay between culture, structure, professional ideology and the functioning of child welfare systems.

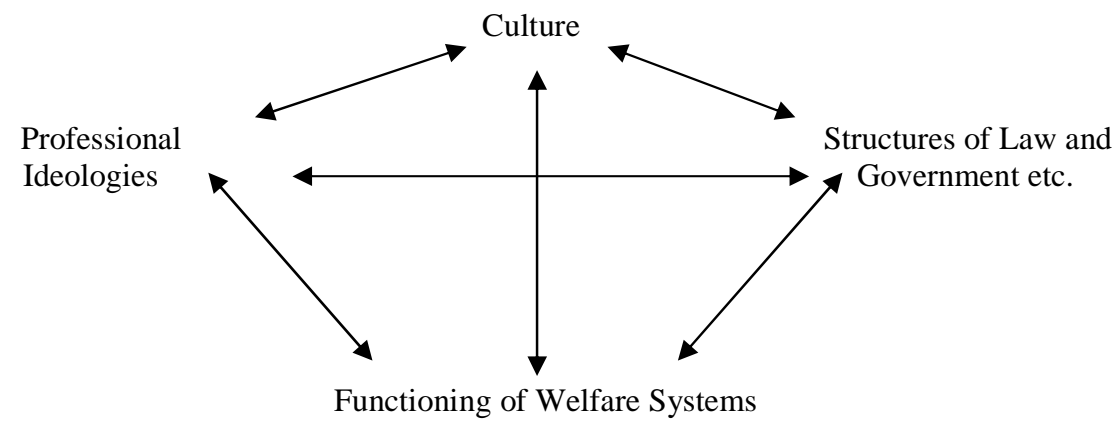




\section{The dominance of culture}

Although culture, structures and professional ideology all interact to shape functioning of child welfare systems, their effects are not necessarily equally powerful. There is some evidence from the comparative studies referred to earlier in this paper, that culture may be the most powerful factor. Esping-Andersen linked welfare regimes and political philosophies. Gilbert similarly supports the view that there is a cultural divide between child welfare systems focused on family support, and those focused on child protection, and that this divide is related to the wider social philosophy of the country.

Gilbert (1997) compared descriptions of nine European and North American child abuse reporting systems. One focus of his comparisons was on the use of laws concerning the mandatory reporting of child abuse. He divided the countries he compared between those with a 'child protection' orientation and those with a 'family service' orientation. Two of the three 'child protection' oriented countries had mandatory reporting laws, and the third, England, has strict professional guidelines that amount to something very similar. Three of the six 'family service' oriented countries also had mandatory reporting laws. Surveying the systems at the end of his book, Gilbert (1997) observed "The presence of mandatory reporting laws does not appear to be linked to child protective or family service orientations" (p. 234). These structures (mandatory reporting laws) therefore did not determine how the system worked.

Gilbert (1997) also considered the kind of intervention and treatment approaches that were used in various systems:

'Although mandatory reporting operates in both child protection and family service-oriented systems, the filing of a report in each of these two systems has somewhat different implications. Reports filed in 
systems with a protective orientation prompt investigations that are more legalistic and vested with the coercive powers of the state than those filed in systems with a service orientation, which emphasises therapeutic and voluntary measures' (p. 235).

This suggests that neither structure nor professional ideology determined the response of the system. The way that the laws were used did not appear to be the result of the application of the professional ideology of social work, because, as has been previously noted, the professional ideologies of social work are very similar crossnationally (Hetherington, Baistow, Katz, Mesie and Trowell, 2002). It can be argued that both structures and professional ideologies were less significant for the overall functioning of child welfare systems than the culture within which they operated. Gilbert's (1997) work suggests that in child welfare systems culture may be most powerful factor in determining overall system functioning.

If it is the case that culture has the lead role in determining functioning, then the political philosophy that the state embodies will directly affect the experience of families in need of support. The culture of a society is expressed both through the structures of the society and through the use that society makes of those structures. The allocation of resources and delivery of services can be seen as a facet of culture, expressing both the means by which it is culturally acceptable for services to be delivered and the value that society places on different kinds of support. Countries that have similar values in relation to child welfare may thus have different ways of providing these services.

Sweden and Germany are both countries which have a 'family service' orientation (Gilbert, 1997) to child welfare. However, Sweden has mandatory reporting, while Germany does not. Information generated from the discussions with practitioners from these countries (Hetherington, Baistow, Katz, Mesie and Trowell, 
2002) shows how these similarities and differences affect social work practice and the experience of families. In both Sweden and Germany, the child welfare systems put high levels of resources into family support and value preventive work, but these two countries delivered services differently and had different expectations. In Sweden, the state is seen as representing the community of citizens and as the provider of social security (in the broadest sense). In Germany, it is expected that the delivery of the service should be organised within local communities, although the state has an important responsibility for making sure that proper provision of child welfare services exists and that services are effective. The principle of subsidiarity, which is fundamental to German social structures, requires that all interventions take place at the least formal level that is feasible (Schäffer, 1995).

In practical terms, these differences in culture mean that in Sweden there are very few non-governmental organisations while in Germany there are many. In Sweden, social workers participating in a comparative study (Hetherington, Baistow, Katz, Mesie and Trowell, 2002) expected that families would accept state support. They thought that families expected that the state should offer help and were likely to trust social workers. Mandatory reporting was seen as a means of ensuring that help was made available.

In Germany, social workers were very concerned about establishing trust with families because the voluntary engagement of families was considered pivotal. The German social workers thought that families had a right to help, but they knew that families also had choice about the source of help, because of the proliferation of different non-governmental agencies. Families' trust had to be earned.

Both countries expressed a similar valuation of the importance of preventive and supportive work with families as an integral aspect of their child welfare systems. 
On the other hand, they had different political philosophies. As a result, in spite of holding similar values about preventive work, these child welfare systems were substantially shaped by different political philosophies, and the experience of families was different.

\section{Child welfare and welfare regimes}

Esping-Andersen (1990) proposes a categorisation of welfare regimes according to the socio-economic philosophy demonstrated in relation to their health and welfare benefits systems. Countries where the state was heavily involved in the delivery of services, were described as social democratic. Countries that structured the delivery of services through other, non-governmental, means, were considered conservative. In both of these groups, the philosophy expected that, if citizens were sick or unemployed, the state had a responsibility to see that they had access to help, whether assistance was provided by the state or by others. In the countries categorized as liberal, there were very low requirements for state responsibility and high expectations that individuals should make their own provisions for their own health and social well being.

If it is accepted that culture is the dominant force, this explains the convergence between Esping-Andersen's (1990) typology of welfare regimes and Gilbert's (1997) categorisation of child welfare systems. All the countries which Gilbert describes as focusing on child protection are categorised by Esping-Andersen as having liberal welfare regimes; while the countries that Gilbert describes as focusing on family services are categorised by Esping-Andersen as having social democratic or conservative welfare orientations.

It is also the case that the countries with social-democratic welfare regimes had mandatory reporting of child abuse, while the conservative welfare regimes did 
not. For example, Sweden, which has a social democratic welfare regime, with a family support focussed child welfare system, has mandatory reporting; while Germany, which has a conservative welfare regime, and a family support focussed child welfare system, does not. The differences in political philosophy between Sweden and Germany identified by Esping-Andersen (1990) in relation to welfare regimes is reflected in the use or non-use of mandatory reporting laws identified by Gilbert (1997).

Gilbert (1997) worked from formal descriptions of child welfare systems written by academics in each country. Working from inter-country comparisons based on qualitative data from social work practitioners, we identified the same divisions between types of child welfare systems. The English speaking countries in our research (Hetherington, Baistow, Katz, Mesie and Trowell, 2002) were England, Scotland, Northern Ireland, Ireland and Australia (Victoria). All (except in some respects Scotland) had child welfare systems characterised by a focus on child protection, distrust of state intervention, and a legalistic approach. These systems were crisis orientated, with an emphasis on rights and individual responsibility. Their systems treated family support and child protection as discrete processes.

The Nordic countries, with social democratic welfare regimes, and the other European countries with conservative welfare regimes, had "family service" orientated child welfare systems. The differences between the two groups in relation to child welfare was reflected the role of the state in delivering services. In spite of differences stemming from a very different view of the relationship between the state and the individual, both the Nordic and the other European countries in our studies had holistic child welfare systems that treated prevention, support and the protective responses to child abuse as parts of a whole. The dualistic child protection 
orientation, with a division between services for family support and for child protection, in our investigation appeared to be a consequence of operating within a liberal welfare regime. The table below sets out the brood pattern of welfare regimes and child welfare services for the majority of countries in the European Union and some states in North America and Australia ${ }^{5}$.

Table 1: Welfare regimes and child welfare systems

\begin{tabular}{|l|l|l|l|l|}
\hline \multicolumn{2}{|c|}{ Welfare regime } & $\begin{array}{l}\text { 'Social- } \\
\text { democratic' }\end{array}$ & 'Conservative' & 'Liberal' \\
\hline $\begin{array}{l}\text { Child welfare system system: } \\
\text { 'Family service' } \\
\text { orientation }\end{array}$ & $\begin{array}{l}\text { state service } \\
\text { delivery }\end{array}$ & $\begin{array}{l}\text { Nordic } \\
\text { Countries }\end{array}$ & & \\
\cline { 2 - 5 } & subsidiarity & & $\begin{array}{l}\text { Continental } \\
\text { European } \\
\text { countries }\end{array}$ & \\
\hline $\begin{array}{l}\text { Dualistic system: } \\
\text { 'Child protection' } \\
\text { orientation }\end{array}$ & & & $\begin{array}{l}\text { English- } \\
\text { speaking } \\
\text { countries }\end{array}$ \\
\hline
\end{tabular}

All the countries listed below were covered by Gilbert (1997) and/or Hetherington et al. (1997 and 2002).

1. Norway, Sweden, Denmark and Finland.

2. Belgium, France, Germany, Greece, Italy, Luxembourg and the Netherlands.

3. The UK, Ireland, California, Canada and Australia (Victoria).

\section{Making changes}

Problems relating to the well being of children take place within a complex and potentially conflicting web of interests among parents, children, the community and the state. Parents are family members with responsibilities and duties towards their children, individual citizens with rights, as well as members of the community. Children are family members, but dependent on adult care, and they are also individuals, as well as future citizens with restricted rights. We all have expectations of the role of the state in relation to the individual and family, the family in relation to 
the child, and the community in relation to children and families. These expectations find expression in the functioning of child welfare systems.

A study of the differences between child welfare systems can help us to develop new ideas about changes that we wish to see. It also makes us more aware of the challenges involved in making changes in child welfare systems. Comparisons with other countries show how decisions made about services for families reflect attitudes about family autonomy and state intervention that are part of the culture in which professionals, communities, families and children live. It follows that if we are attempting to introduce changes into our child welfare systems, we have to be very aware of the cultural context in which any changes will take effect. This is not to say that change cannot take place, it obviously does. But to make intentional changes that achieve their objectives without unintended consequences is difficult. Changes need to take into account expectations shared by workers, families and policy developers about the relationship between the state and the individual, the responsibilities of the family and the community, and the needs of children. If the changes are not consonant with these expectations, they have much less chance of acceptance and success.

This may explain why in England, the efforts of the Department of Health to shift the focus of the system from child protection to family support have had minimal success. England has a long-standing political philosophy, particularly emphasized since the 1980s, setting a high value has been set on the freedom of the individual from state interference. This ethos of individual autonomy and state minimalism does not readily support changes that would increase the involvement of the state in the welfare of children. There is a contradiction between discouraging reliance on state support and encouraging more supportive interventions with families. In countries like 
England, initiatives to introduce a brooder child welfare perspective and to encourage the development of preventive services, need to make extremely strong positive arguments for such changes and to use strategies that influence multiple levels of the community, and government system. Working with international comparisons reinforces our awareness of the full complexity of trying to change something as central to civil society as its child welfare system.

There is a specific problem in trying to develop a holistic, truly integrative, child welfare system in the context of a liberal welfare regime with an emphasis on individual responsibility. Front-line service workers can do a certain amount, perhaps more than they realise, by the use they make of the existing structures. But there are limits to what they can do. In order to legitimise the changes that would need to be made, the challenge to existing expectations and assumptions needs to come from high levels of influence and power. Moving from child protection to child welfare entails a shift of resources and attention from protection to prevention. This raises anxieties that abused children will not be protected and that children will die. Making changes will entail taking risks, and risks that involve children are politically sensitive. Policy makers and politicians who want to change the system will have to rethink structures, reallocate resources, and be prepared for criticism that children's lives are being put at risk. It may help them to know that in other countries, strategies that seem to us to be so dangerous are seen as the safest and the most truly protective. 


\section{References}

Baistow, K. (2000) Cross-national research: What can we learn from intercountry comparisons. Social Work in Europe, 7(3), 8-13.

Baistow, K., \& Hetherington, R. (1998) Parents' views of child welfare interventions: An Anglo-French comparison. Children and Society, 12, 124-133.

Baistow, K., \& Wilford, G. (2000) Helping parents, protecting children: Ideas from Germany. Children and Society 14, 343-354.

Clasen, J. (ed.) (1999) Comparative social policy. Concepts, theories and methods. Oxford: Blackwells.

Cooper, A., Freund, V., Grevot, A., Hetherington, R., \& Pitts, J. (1992) The Social Work Role in Child Protection: An Anglo-French Comparison. London: Centre for Comparative Social Work Studies, Brunel University.

Cooper, A., Hetherington, R., Baistow, K., Pitts, J., \& Spriggs, A. (1995) Positive Child Protection: A view from abroad. Lyme Regis: Russell House Publishing.

Department of Health (2000) The framework for the assessment of children in need and their families. London: Stationery Office.

Esping-Andersen, G. (1990) The Three Worlds of Welfare Capitalism. London: Polity Press.

Esping-Andersen, G. (1999) Social Foundations of Postindustrial Economies. Oxford: Oxford University Press.

Gilbert, N. (ed.) (1997) Combatting child abuse: International perspectives and trends. Oxford: Oxford University Press.

Grevot, A. (2001) Voyage en protection de l'enfance. Une comparaison européenne. Paris: Vaucresson CNFE-PJJ. 
Hantrais, L., \& Mangen, S. (eds.) (1996) Cross-national Research Methods in the Social Sciences. London: Sage.

Hellinckx, W., Colton, M., \& Williams, M. (eds.) (1997) International perspectives on family support. Aldershot: Ashgate.

Hetherington, R. (1996) The Educational Opportunities of Cross-National Comparison. Social Work in Europe, 3(1) 26-30.

Hetherington, R. (1998) Issues in European Child Protection Research. European Journal of Social Work 1 (1) 71-82.

Hetherington, R., Baistow, K., Katz, I., Mesie J., \& Trowell, J. (2001). The $\underline{\text { welfare of children with mentally ill parents: Learning from inter-country }}$ comparisons. Chichester: John Wiley.

Hetherington, R., Cooper, A., Smith, P., \& Wilford, G. (1997) Protecting Children: Messages from Europe. Lyme Regis: Russell House Publishing.

Hetherington R., \& Piquardt, R. (2001) Strategies for survival: Users' experience of child welfare in three welfare regimes. $\underline{\text { Child and Family Social Work, }}$ $\underline{6}(3)$ 239-249

Jones, C. (1985) Patterns of Social Policy: An Introduction to Comparative Analysis. London: Tavistock.

Mabbett, D., \& Bolderson, H. (1999) Theories and Methods in Comparative Social Policy. In J. Clasen (ed.) Comparative Social Policy. Concepts, Theories and Methods. Oxford: Blackwells.

Millar, J., \& Warman, A. (1996) Family Obligations in Europe. London: Family Policy Studies Centre.

Øyen, E. (ed.) (1990) Comparative Methodology, Theory and Practice in International Social Research. London: Sage. 
Pringle, K. (1998) Children and Social Welfare in Europe. Buckingham: Open

University Press.

Schäfer, H. (1995) Legal notebook: the principle of subsidiarity. Social Work

in Europe, 2(3), 52-53.

Soydan, H. (1996) Using the vignette method in cross-cultural comparisons. In

L. Hantrais \& S. Mangen (eds.) Cross-national Research Methods in the Social

$\underline{\text { Sciences. London: Sage. }}$

Soydan, H., \& Stål, R (1994) How to use the vignette technique in cross-

cultural research. Scandinavian Journal of Social Welfare, 3 , 75-80.

\footnotetext{
${ }^{1}$ The Centre for Comparative Social Work Studies was set up in 1991 by Professor John Pitts. It is part of the Department of Social Work at Brunel University and works in co-operation with practitioners and researchers in social work agencies and universities across Europe.

${ }^{2}$ See, for example, Jones (1985), Esping-Andersen (1990, 1999), Øyen (1990), Hantrais \& Mangen (eds.) (1996), Clasen (ed.)(1999).

${ }^{3}$ The specialist journals, the European Journal of Social Work, and Social Work in Europe are good sources, but there are increasing numbers of papers in mainstream child welfare journals. There is also a small body of literature on the use of comparative studies in social work research and education, e.g. Soydan and Stahl(1994), Hetherington (1996 \& 1998), Soydan (1996), Mabbett \& Bolderson (1999), Baistow (2000).

${ }^{4}$ The author and colleagues have adopted the use of 'administrative' from the French, to fill the gap, and use it to describe the 'voluntary', or 'non-statutory' parts of the child protection system.

${ }^{5}$ All the European countries studied by Gilbert (1997) and Hetherington et al. (1997 and 2002) are members of the European Union, except Norway, which conforms to the same pattern as the other Nordic countries. Neither Gilbert nor Hetherington et al. includes Austria, Portugal or Spain.
} 


\section{SOCIAL WORK}

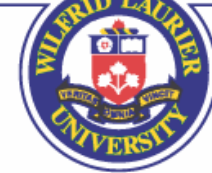

Partnerships for Children and Families Project

Wilfrid Laurier University

Waterloo, Ontario, Canada, N2L 3C5

Email: partnerships@wlu.ca

Local: (519) 884-0710 ext.3636

Toll Free: 1-866-239-1558

Fax: $\quad$ (519) 888-9732 